\title{
Higher-Order Thinking in Foreign Language Learning
}

\author{
Ascensão Bastos \\ mariaascensaobastos@aecarlosamarante.pt \\ Maria Altina Silva Ramos \\ Universidade do Minho \\ Braga-Portugal
}

\begin{abstract}
A project is being conducted in English as a foreign language (EFL), involving eleventh graders in formal and non-formal learning contexts, in a Portuguese high school. The goal of this study is to examine the impact of cognitive tools and higher-order thinking processes on the learning of EFL and achievement of larger processes oriented to action, involving problem solving, decision-making and creation of new products. YouTube videos emerge as cognitive tools in the process. Final results show major differences concerning learners' achievements. Learners have developed higher-order processes oriented to action, in particular their ability to learn, to transfer the skills developed to different contexts and apply them effectively in EFL communicative situations. This paper discusses: a) major theories that support the integration of cognitive tools and thinking processes within the curriculum, focussing on the English language learning; b) some of the activities and materials; c) the final findings.
\end{abstract}

Keywords: Cognitive Tools, Higher-Order-Thinking, Self-Regulation Process, Transfer, YouTube videos.

\section{INTRODUCTION}

Continuous and increasingly complex new global transformations are under way in the sociocultural and technological fields demanding the continuous acquisition of knowledge and the development of specific skills. The need to be prepared to this fast changing world is upon us, urging improvement in the quality of our thinking, new approaches to teaching and learning, new literacy tools, and a good command in foreign languages [1].

The emergence of a digital culture and widespread use of Information and Communication Technologies (ICTs), comes up as a driver and a support for these realities providing the acquisition of new skills, helping us learn more effectively, improving participation in public and active life, promoting communication across linguistic and cultural borders, fostering innovation in schools and creating competitive advantage in the future [2].

In this context, the integration of ICTs in school - viewed as a means to better learners' thinking, knowledge, collaboration and communication - is regarded as a response to the needs and expectations of the YouTube and Google-eyed generation 1 who perceive education as a way to learn what they need for tomorrow [5]. Although the kinds of jobs they will be doing in the future cannot be fully predicted, the development of the ability to think for oneself, the

\footnotetext{
${ }^{1}$ Distinct terms are assigned to the YouTube generation, such as Millennials, Net Generation, Generation $\mathrm{X}$, and the Nintendo to name but a few [3] [4].
} 
purpose that runs through all other educational purposes, will help them get the knowledge and skills they will need in the long run. Such a requirement calls for the need to change our thinking in foundational ways, the need for regular exercise of disciplined thinking, the need for intellectual development and personal growth [6], rejecting the so common uncritical, simplistic and unimaginative thinking hand in hand with superficial solutions that do not combine with the sophisticated technologies and incessant complex problems we face in the ever-more changing world.

In parallel, the development of English as a foreign language (EFL), is considered essential for active participation in today's society, given its privileged role as the language of international communication [1]. All-important is the development of learner's whole personality and sense of identity in response to the enriching experience of otherness in language and culture [7].

Continuous development of thinking processes, foreign language skills, and digital skills is essential for responding to the challenges demanded by the current era of globalization. So it is of paramount importance to redefine methodological practices, welcoming technological approaches and making the curriculum more relevant by developing higher-order processes oriented to action, in particular the ability to communicate effectively (EFL) and the ability to learn and become independent, self-directed learners.

\section{Theoretical Framework}

\section{A Shif Of The Paradigm In The Digital Age}

The process of European convergence recommends transition from knowledge to competence and from teaching to learning, placing the learner at centre stage [8]. It seems the constructivist perspective falls within this purpose. Regarded as a theory of learning, constructivism conceives it as a dynamic and student-centred process, being the teacher's role to prepare an innovative environment that supports and encourages students in discovery, exploration and construction of their knowledge. Students who construct their own representations will better grasp and remember what they learn. This process entails the processing of previous knowledge [9], complete delivery and availability of the learner who continuously disciplines and exercises his thinking. Emphasis is placed on the learners' cognition, reflection and knowledge construction [9].

A constructivist view of learning underscores, however, that effectiveness of learning depends on learners' desires and the subject matters they involve with. Their active participation in education is interrelated to issues belonging to the sphere of their concerns and their emotions. Educational psychologists [9] [10] [11] point to the role emotions play in the relation between new knowledge building and pre-existing knowledge to be remembered. Actually, such a view closely parallels contemporary work in the field of neuroscience, exemplified in the writings of Damásio [12]. The neuroscience's Portuguese thinker argues that emotions, which are rooted in physicality, profoundly influence not only what people reason about, but how they reason. Without emotions, people can't make wise decisions. Accordingly, Lipman [13], referring to caring thinking as a third prerequisite to higher-order thinking, questions the role of emotions when we have choices and decisions to make, and these choices and decisions are the leading edges of judgement. In parallel with the mentioned authors, George Siemens [14] places value on the emotional factors involved in knowledge creation and dissemination we do not function according to formulas and rules. We exist in a rich interplay of multiple domains (...) where our emotions, desires and logic are expressed in dialogue and debate with others. The way in which we interact with knowledge is influenced by our emotions.

Emotions and concerns, hopes and wishes, dialogue and debate, collaboration and interactivity, connectivity and immediacy, speed and multitasking, come out quite strongly in this 
generational cohort born in the digital age. Understanding the true significance of these traits, among others, means understanding the future and how the education setting and society need to change today [3].

The skill-based approach requires a change of paradigm from teacher-centred to studentcentred learning and a shift from traditional methods to an entirely new approach, providing youngsters the development of their full potential [15]. Teachers are expected to work as facilitators, collaborators and mediators between the learner and modern sources of information. Concerning the changing and speeding of knowledge and learning contexts in the digital age, Siemens [14] observes that boundaries between teacher and student gradually dissipate and change the dynamics between them the educator becomes a supporter (not the centre), (...) learners find value in their aggregated perspectives, learners become content creators, and learning is continuous, sustained and exploratory. Siemens' beliefs [14] are consistent with Tapscott's [3] in that they illustrate the change in current hierarchies with the appearance of each new technology for the first time, in one domain (how to use computers), the students will be the teachers and the teachers will be the students (...) they are replacing a culture of control with a culture of enablement.

Conditions have significantly changed due to new opportunities provided by technology. Over the last three decades, technology has reorganized how we live, how we communicate and how we learn [5]. Youngsters' profile should be in tune with how they learn. The development of school curriculum cannot be done separated from the knowledge and skills youngsters nowadays possess. Schools should bear in mind the articulation of their knowledge with school knowledge and use youth's skills concerning the use of technologies [16]. Accordingly, Tapscott [3] claims that for many kids, using the new technology is as natural as breathing, adding Net Geners are the new scrutinizers. Trust but verify would be an apt motto for today's youth. (...) they are assessing and scrutinizing the jumble of facts that are often contradictory or ambiguous. On the other hand, Vargas Llosa [17] acknowledges the negative effects of the modern society in his latest book, arguing that the concept of culture has been replaced by the cult of the spectacle directed at an uncritical and undifferentiated mass. In his analysis, the author notes that a kind of conformism, lack of creativity and lack of intellectual effort are prevailing and secluding people from real life and problems.

Unless we wake up the spectator through progressive change in education, approaching learners as persons with their own thoughts, idiosyncrasies, emotions, expectations, and resources, orienting them towards the construction of their own knowledge, to figure things out for themselves, and to participate actively in their own learning, we will not be working toward the advancement of critical societies.

It should be the primary educational role to develop youth's ability to use their mind to its fullest potential, fostering reasoning and judgement, and their ability to communicate effectively and to use technologies skilfully.

Therefore, it's important to create a learning environment led by self-consciousness, and devise sustainable school approaches that align with younger people styles and desires and figure out which technologies might better enable these practices. It stands to reason that innovation does not lie in the power digital tools bring into the classroom, but rather in how teachers work to empower and enrich learners, developing a positive sense of themselves, individual accountability and civic engagement. 


\section{Higher-Order Thinking}

Recent educational approaches consider higher-order thinking essential for tackling the complexities of contemporary life. According to Lipman [13] to bring about higher-order thinking at school is significantly greater than the capacity of any alternative approach. Yet, in Siemen's words [14] higher-level cognition is hard to implement large scale, as it requires deep learning, and critical thinking.

Bassham et al. [18] consider that in many high schools, the emphasis continues to be on lowerorder thinking. Students are expected to passively absorb and retain information for test-taking purposes. Instead of teaching students what to think, the main educational goal should be to teach students how to think, that is, how to become independent, self-directed thinkers and learners. According to the authors, higher-order thinking relates to the active and intelligent evaluation of ideas and information. Similarly, Bloom's taxonomy, according to Airasian et al [19], classify memorization and recall of information as lower-order thinking whereas analysing, synthesising and evaluating are classified as cognitive skills that are beyond the lower-level thinking.

Numerous authors focus on the subject presenting their own definition of higher-order thinking [11], [13, [19], [20]. The available choices may pose some confusion; still, key features can differentiate skills. Rather than giving a precise definition Resnick [21] points out some of its characteristics: it is nonalgorithmic, it involves the application of multiple criteria, and selfregulation of the thinking process, it yields multiple solutions, it is effortful and it tends to be complex. In Jonassen's viewpoint [22] the essential core of higher order thinking is the point at which thinking intersects with an action. The aim is to produce some kind of outcome - a design, a decision, or a solution.

\section{The Integrated Thinking Model}

Jonassen's conception of thinking [22] [23] is consistent with global, systematic and explicit conceptualizations of critical and creative thinking. The author's great merit lays on the construction of meaningful thinking with the support of cognitive tools in a constructivist environment.

Jonassen [22] [23] proposes The Integrated Thinking Model, which defines complex thinking as an interactive system, integrating different kinds of thinking and associated interwoven skills. The model aims at describing the mental processes (also referred to as thinking processes, thinking skills, thinking strategies) involved in the construction of meaningful knowledge, regarded as a continuous process. These thinking processes mean making using of content, critical and creative thinking interdependently in order to produce some kind of action-oriented processes. The author refers to complex thinking as goal-directed, multi-step, strategic processes, such as designing, decision-making, and problem solving. In his opinion, this is the essential core of higher order thinking.

At the centre of the Model are complex thinking skills that combine content/basic thinking, critical thinking and creative thinking (definitions above).

As the Integrated Thinking Model is regarded as an interactive system, skills are not developed separately. The relationship between the skills is dynamic and interdependent since learners mobilize the different types of thinking systemically. Figure 1 shows The Integrated Thinking Model with different types of thinking and associated skills. 


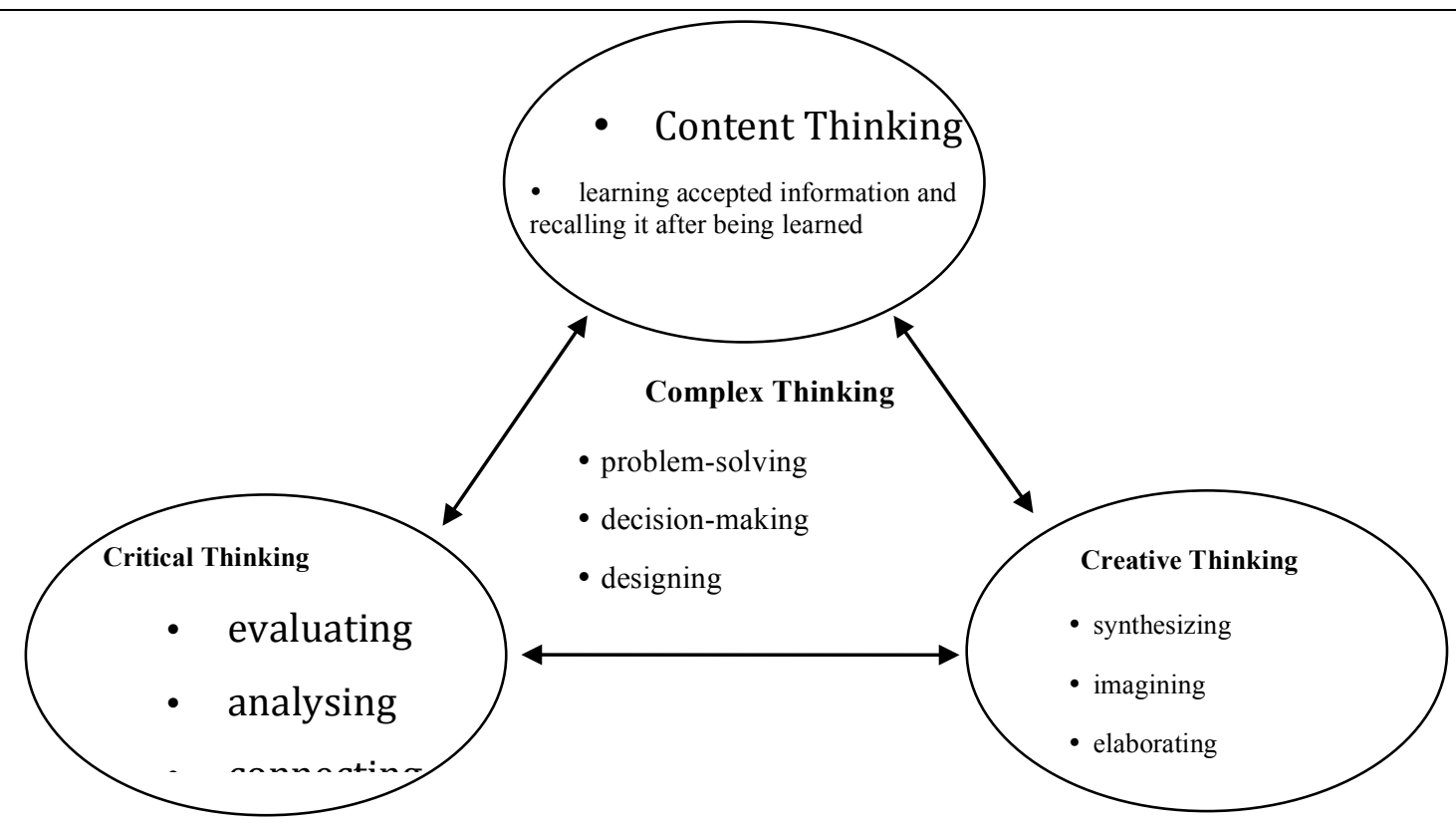

Figure 1. Integrated Thinking Model $[22,23]$ (adapted and abridged)

\section{Cognitive Tools: Youtube Videos}

There are a number of reasons that support the use of YouTube videos as cognitive tools. For one hing, they meet Jonassen's set of criteria [22] [23] for assessing cognitive tools. They present a simple but powerful formalism that require deep thinking despite its software being easily learnable, they allow knowledge representation in different subjects and subject-matter domains, they provide transferable skills that can facilitate thinking in different fields, and they engage learners in higher-order thinking. Moreover, they fall into different major subject categories, ranging from education to science, and they may be considered both as primary or secondary sources in case information authenticity is confirmed in credible sources, or if a reliable publisher can be traced.

YouTube videos work as cognitive tools and intellectual partners since learners can't use them effectively without thinking deeply about the content they are constructing and representing [23].

Nikos Theodosakis [24] stresses that the production of films triggers the development of multiple skills of critical thinking in each of the steps that it entails: films begin with ideas. They evolve through brainstorming, research and discussion. In the planning stage, they require the articulation of a creative vision through written scripts, visual storyboards and oral presentations. In execution they demand planning, organization, problem solving and maintaining focus. In editing they require analysis, more problem solving, and the distillation and synthesis of clear, concise stories, investigations and arguments.

Moreover, YouTube videos provide EFL learners with a favourable learning environment. Duffy and Cunningham [25] note that learning environments dominated by interactive dynamics favour the development of language skills. Toro [26] also considers that building hypermedia presentations in foreign languages facilitates language learning since these are personal representations of students' knowledge.

However, as noted before, being part of a joint learning system together with the learner and the activity, cognitive tools should be accompanied by appropriate learning activities and 
learner performance should be assessed in the context of tools' use, a perspective properly acknowledged by Kim and Reeves [27].

Although Moodle forums have been used throughout the process as cognitive tools, they will not be accounted for in this article. However some of participants' posts are included in the article to illustrate researchers' observations.

\section{METHODOLOGY \\ Research Design: Problem And Research Questions}

Bearing in mind its specificity, the research is considered a case study, defined by Yin [28] as a method that contributes to the knowledge of the individual and the group and associated phenomena, allowing to retain the holistic and meaningful characteristics of real-life events.

The goal of the study is to develop higher-order processes oriented to action, in particular the ability to communicate effectively (EFL) and the ability to learn and become independent, selfdirected learners, by asking the following questions: a) What is the effectiveness of explicit development of higher-order thinking skills on EFL learning? b) What is the effectiveness of cognitive tools on the process? c) Do learners effectively apply and transfer the knowledge newly gained into different EFL learning contexts and daily life situations, accomplishing larger action-oriented processes?

\section{Data Collection And Analysis}

Qualitative and quantitative approaches are combined in the project following Russek and Weinberg [29] claim that both procedures may give insights that neither type of analysis can provide alone.

Data collection includes field notes from participant observation, the first set of self-regulation sheets, which include learners' self-assessment, Speaking self-assessment grids, videos posted on YouTube, diaries' analysis and assessment (mentioned ahead), and data from the forums.

Some qualitative data is provided along the description of the process. Actually, as the teacher is the researcher in this study, it is difficult for the authors, to adopt a neutral position on learners' performance.

The software Statistical Package for the Social Sciences (SPSS) and spreadsheets are used for statistical analysis of quantitative data. Cross-tabulations are carried out to provide an overall picture of the data, exploring relationships between thinking skills (Table 1 and Table 2), and relationships between thinking skills and EFL Speaking skills (Table 3 and Table 4).

\section{Guidelines Underlying The Project}

\section{THE RESEARCH PROJECT}

Jonassen's conception of thinking [23] falls within our aims. In this particular study, the researchers address themselves to foster learners' higher-order processes oriented to action in the light of the author's view. The Model selected by the author has been adapted to the context, and to the approach accordingly. Thinking strategies and universal intellectual standards are explicitly developed throughout the practice, and, English as a foreign language, is integrated and developed in the process simultaneously.

Learning is approached as an integrated and systematic process. Critical and creative thinking processes are developed as the driving force of foreign language learning with the help of cognitive tools and particular content learning in mind. In this sense, the English foreign 
language is learnt as a form of thinking as students learn to reflect, investigate, evaluate, analyse, and question about real- world problems [30], activating not only the linguistic structures of the foreign language but also pragmatic and sociolinguistic components. On the whole, general competences, including the existential competence (learners' personality features, motivations, attitudes, beliefs), and the ability to learn (study skills and heuristic skills) are developed [7].

Further still, Jonassen [23] advocates that collaboration is one of the essential means for helping learners construct their own knowledge representation. Groups of people can collaboratively build more meaningful knowledge than individuals alone (...). Collaborative groups must cooperate. Tapscott [3] emphasizes that learning is a social activity and learners do best when they construct their knowledge engaged in relationship-oriented activities. Paul and Elder [6] also defend that when learners cooperate with each other, they are led to think within multiple perspectives, this is, to learn to see mistakes in their own thinking and be able to credit and appreciate opposing beliefs, and change their own opinions when faced with better reasoning. Similarly, Johnson and Johnson [31] believe that cooperative teams achieve higher levels of thought and retain information longer than learners who work alone. So it is with cognitive tools, which are best used collaboratively and cooperatively among learners, requiring them to think in new ways and while working on a knowledge construction process [23].

In order to allow fully participation of students in the project, teachers, closely supervising the process, let students organise themselves into groups of three elements since they usually tend to form homogeneous groups, composed of like-minded and similar-ability students. However, as improvement of English communication skills is the main of the set goals in the project, the different groups are required to incorporate a low-ability peer in terms of the English language use.

Even though the four language skills (Listening, Reading, Speaking, Writing) are developed in the integrated approach, the central focus of the study is Speaking (spoken production and interaction). High importance is generally attributed to interaction in language use. Learning to interact involves more than learning to receive (Listening, Reading) and to produce utterances (Speaking, Writing). In interaction both production and reception alternate, and may in fact overlap in oral communication [7].

\section{CONTEXT}

The research project has been developed and refined over four years in a Portuguese secondary school. The current article reports on to the 2013 school year experience. It has involved three EFL teachers (one of the teachers engaged in the process is the researcher, and the co-ordinator of the project) and a total of eighty-five $11^{\text {th }}$ graders attending four mixedability classes (high-achieving students and low-achieving students concerning all academic subjects). The students were between 16 and 17 years old and had attended EFL for six years in different public high junior schools.

Students' reasoning skills were first assessed throughout $10^{\text {th }}$ year (qualitative evidence) as EFL high school teachers repeatedly witnessed that a vast majority of students had problems using the elements of reasoning in accordance with appropriate intellectual standards [6], and make sense of what they were learning. Students were engaged in different activities, such as writing reviews and debating issues related to the subject areas being studied in the $10^{\text {th }}$ grade. Findings showed that the largest group of students, amongst other problems, did not formulate and present convincing reasons in support of conclusions, their reasoning was not guided by 
the most significant intellectual standards, they were far away from considering any criteria to evaluate their judgements, and inferring information or relating the subject in discussion to other subjects and to meaningful and real life situations was out of question. Instead most students provided simple and vague arguments, and confined themselves to short and emotional exchanges, expressing themselves unclearly, imprecisely, and inaccurately.

In the 11th-grade students undertook the action research project with their previous year EFL teachers. The research project took a total of 33 lessons (90-minute-a-lesson) and was developed within a formal and non-formal English learning environment (EFL).

\section{Learners' Assessment}

For self-regulated learning to be effective, learners need to be able to accurately assess their own performance on a learning task [32] [33]. Self-assessment, one of the key features of higher-order thinking [21] comes up as an integral part of learners' learning.

Self-assessment grids were specifically designed for the project, articulating learning objectives and students' effective learning. Criteria related to description issues as well as measurement issues are included. The description and categorization used in the selfassessment grids are related to theories of language learning [7], and thinking strategies theoretical principles [23]. While relating to theory, the description is context-relevant and user-friendly, aiming to encourage learners to think further about their capacities at a given level, this is, what the learner can do and how well he can do it [7]. Hence, scales adopted to assess learners' abilities are likely to help learners make reasonably consistent distinctions and to show their progression. The Council of Europe's Framework of Reference for Language is used as a benchmark for self-regulation of the process.

Different grids were designed according to the purposes. Three levels were considered to assess the development of critical and creative processes in English as a foreign language (EFL): Level1 (L1) - basic level; Level 2 (L2) - intermediate level; Level 3 (L3) - advanced level.

Principles of ease of use determined the terminology adopted (L1, L2, L3), since learners are not familiar with the correspondent CEF's levels A2, B1 and B2.

An example of a self-assessment grid is presented in Figure 2. 


\begin{tabular}{|c|c|c|c|c|}
\hline & \multicolumn{4}{|c|}{ EVALUATE INFORMATION } \\
\hline & \multicolumn{4}{|c|}{ SKILLS } \\
\hline & $\begin{array}{c}\text { Communicative } \\
\text { Skills }\end{array}$ & Criteria & Priorities & Fallacies/accuracy \\
\hline \multicolumn{5}{|l|}{ Level 3} \\
\hline $\begin{array}{l}\text { Advanced } \\
\text { Level }\end{array}$ & $\begin{array}{l}\text { I use English } \\
\text { (EFL) all the time } \\
\text { during the } \\
\text { completion of } \\
\text { the tasks. }\end{array}$ & $\begin{array}{l}\text { I establish at least } 5 \\
\text { meaningful criteria. I } \\
\text { share social knowledge } \\
\text { online, commenting on } \\
2 / 3 \text { videos viewed. }\end{array}$ & $\begin{array}{l}\text { establish } \\
\text { priorities, setting } \\
\text { some more } \\
\text { criteria (at least } \\
\text { 2) }\end{array}$ & $\begin{array}{l}\text { I recognize fallacies, } \\
\text { vagueness and bias. I } \\
\text { assess the accuracy of } \\
\text { arguments and facts, } \\
\text { doing some research } \\
\text { online in reliable } \\
\text { sources. }\end{array}$ \\
\hline \multicolumn{5}{|l|}{ Level 2} \\
\hline \multicolumn{5}{|l|}{$\begin{array}{l}\text { Intermediate } \\
\text { Level }\end{array}$} \\
\hline \multicolumn{5}{|l|}{ Level 1} \\
\hline Basic Level & $\begin{array}{l}\text { I frequently use } \\
\text { the Portuguese } \\
\text { language }\end{array}$ & $\begin{array}{l}\text { I establish } 2 \text { or } 3 \\
\text { criteria. I share social } \\
\text { knowledge online, } \\
\text { commenting one of the } \\
\text { videos viewed. }\end{array}$ & $\begin{array}{l}\text { I establish } \\
\text { priorities but no } \\
\text { valid criteria is } \\
\text { added. }\end{array}$ & $\begin{array}{l}\text { There are some } \\
\text { questions about the } \\
\text { credibility of } \\
\text { information } \\
\text { researched online. }\end{array}$ \\
\hline
\end{tabular}

Figure 2. Self-assessment grid (evaluate information)

Learners reflect and fill in the assessment grids corresponding to each of the skills as soon as they complete the tasks.

As learning is approached as an integrated and systematic process, the assessment of communicative skills is integrated in these three-level grids. Though, as the central focus of the study is Speaking, students were provided with an additional three-level EFL Speaking grid. More details regarding the latter grids appear in the Common European Reference for Languages [7].

\section{The Project Implementation}

The development of the research project involves three phases. The first phase consists of fostering thinking and reasoning processes explicitly with the help of YouTube videos, bearing in mind a EFL curriculum content. The socio scientific content area selected for the first phase is Teens and the Consumer Society. The selection of this area is grounded on the national English syllabus, and students' voices. As noted before, the subject matter belonging to learners' sphere of concerns is of much importance to active participation [5] [34] [13].

The second phase entails applying and furthering the knowledge gained (reasoning skills and EFL skills). Learners are now due to produce a video within the same content area Teens and the Consumer Society, attempting at solving the problem (s) detected in the video they have selected and worked through the first phase.

The third phase addresses transfer of newly acquired thinking processes, which have been developed in the context of EFL controversial consumerism issues taken from YouTube videos, to an unfamiliar EFL context - American teenagers' multicultural dilemmas taken from a nonfictional American book [34] - and from this to a new context - Portuguese learners' everyday life problems. The EFL syllabus area of convergence is The Multicultural World. Findings follow each one of the three phases of the project. 
It is important to highlight that all the activities learners were engaged in after the third phase of the project, followed on from the approach, in different EFL contexts, time after time throughout the school year, since the development of higher-order principles governing communicative skills (EFL) must be systematic [35].

\section{Phase 1: Youtube-Based Approach}

As substantive learning can only take place when learners clearly understand the concepts and goals underlying the practice, first lesson begins with the discussion of the research project. The approach, as mentioned before, is to be developed explicitly hand-in-hand with the English discipline-specific content as supported by researchers who claim that critical thinking skills are more likely to develop integrated in an explicit content domain [20] [36] [37].

While constructing their own knowledge, students are expected to develop a range of mental processes, rather than being taught a set of skills. In fact, the aim is to construct knowledge dynamically and interdependently, instead of moving or progressing from one skill to the other sequentially as students are used to do when performing textbook exercises in class. The background data sheets, and the first set of three self-regulation sheets (see key terms and definitions) are handed out at the beginning of the project so that the groups of learners may better understand their assignment. Socratic questioning is used to help students articulate learning goals with set tasks and fundamental principles underlying the whole project, such as universal intellectual standards [6].

To make it easier for the description of the process, skills follow linearly in the article: evaluating, analysing, connecting, synthesising, imagining and elaborating information.

\section{EVALUATING INFORMATION}

Figure 3 illustrates part of the first self-regulation sheet that aims to foster skills concerning the evaluation of information (the assessment part corresponds to Figure 2). 


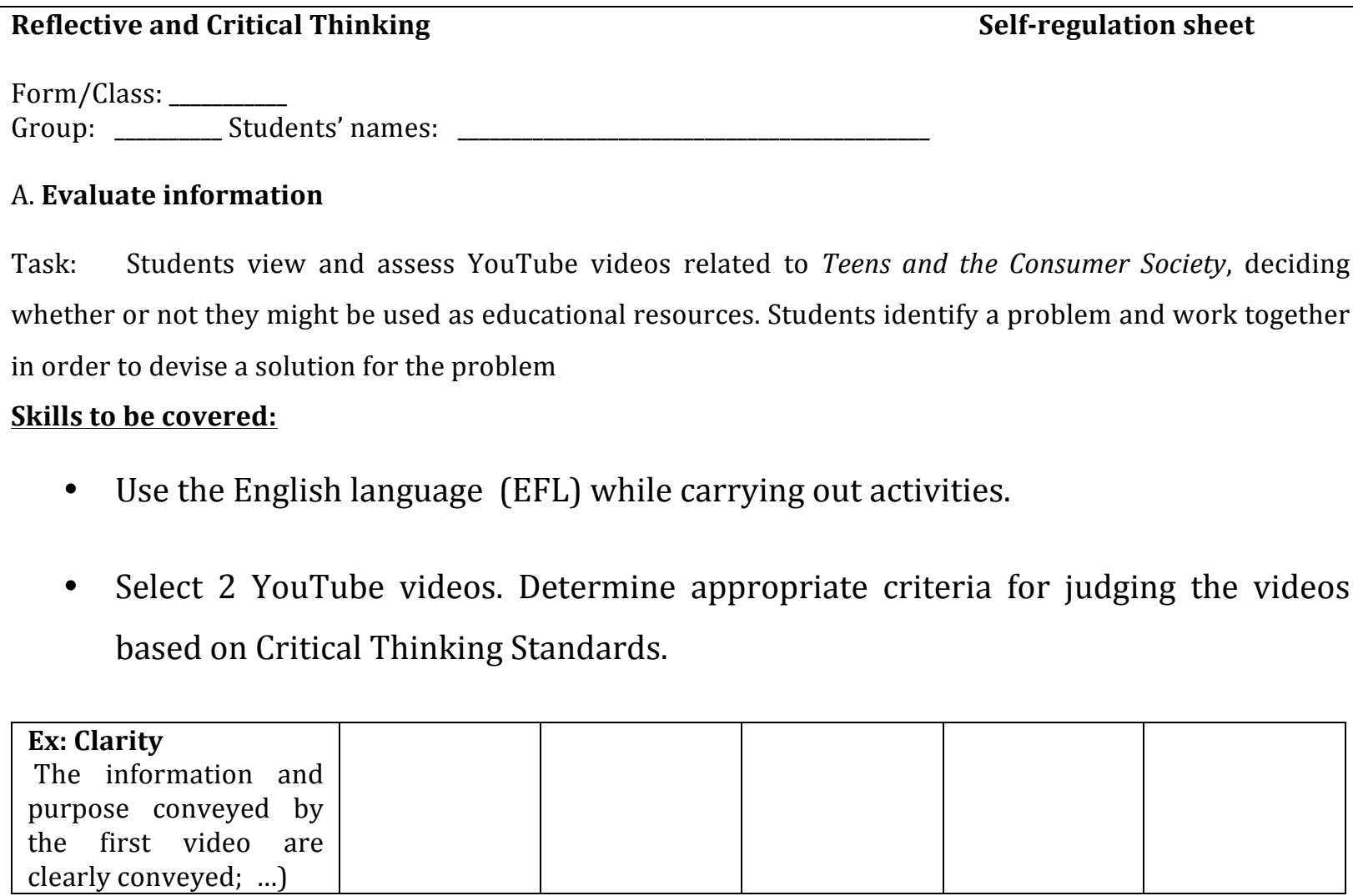

- Establish priorities selecting one of the two videos. Justify, adding personal criteria.

Title of the video selected: Site:

Criteria:

- Recognize fallacies, vagueness, and bias. I assess the accuracy of arguments and facts, doing research on reliable sources.

Accurate arguments/facts:

Credible sources:

\section{Figure 3. Self-regulation sheet (evaluate information)}

The English language is used all through the approach. Activities comprise: selecting two YouTube videos; evaluate the videos based on appropriate criteria (intellectual standards); establishing priorities; recognizing fallacies and errors in reasoning, and verifying the accuracy of arguments and facts in credible sources (fig.3).

Learners discuss the activities suggested in the first set of self-regulation sheets and are made aware that skills are not developed hierarchically but rather interdependently throughout the process.

The groups of learners begin their assignments by doing some research on YouTube English/American videos. The video research comes up as a stimulating starting point for engaging learners actively in EFL lively debates around the controversial issues within the selected reference area Teens and the Consumer Society. Students evaluate the videos they are watching based on the intellectual standards governing critical thinking (clarity, precision, 
accuracy, relevance, consistency, logical correctness, completeness and fairness). As the project is based on problem-solving experiences, students have to identify and choose a problem related to the content they are studying (e.g. shopping addiction or mindless consumers within Teens and the Consumer Society). The aim is to work together throughout the process in order to devise a solution (s) for the problem(s) or make the audience be aware of problems that have no easy solution [38].

While listening attentively to YouTube videos, they make comments on some of them (at least two). A few learners email or sign up for websites (such as Facebook or the Vimeo page) to contact the video directors they have traced, confirming the authenticity or credibility of the source, and sharing social knowledge online [14].

Learners are expected to select two YouTube videos, carefully explaining if criteria is met (if they are governed by intellectual standard). From these two videos, only one is to be chosen. Indeed, learners make a decision and reach a consensus on the video they think best fits the universal intellectual principles, and that might be used as an educational resource. The selected video provides the subject matter-related problem that constitutes the basis for their meaningful learning. Based on it, learners are due to construct, reorganize and create new knowledge, developing thinking strategies explicitly in English as a foreign language (EFL).

Yet, the chosen video has to be scrutinized. Learners look for fallacies and errors in reasoning (such as vagueness, untruths, and bias), and verify the authenticity of information (doing some research online in credible sources). Apparently, some students fail to verify the accuracy of arguments and facts whereas others do some research online but forget the importance of credible sources. Actually, the evidence is not consistent with Tapscott's claims [3] for some seventy per cent of the students do not verify or scrutinize the dubious facts and the reliability of sources. Every so often, attention is paid to the credits that go with the videos before making its selection; learners do some research online in order to find evidence of the reliability of the sources of production (ex: PSA - Penn State University). Occasionally, some groups of learners (about 20\% of the students) show their difficulty in accepting the teacher's questioning as far as their cursory and shallow video choice is concerned. Only when required to analyse the vague thoughts expressed in the video, do they realize the impact of bad decisions and the relevance of in-depth information to successfully accomplish the set goals. Still, some students (about 15\%) show their unwillingness to repeat the process, preferring to keep their conformist position rather than take their effort to the task, taking a firm and uncritical stand as that observed by Vargas Llosa [17]. Sometimes, students' eagerness to be accepted in the group comes up as a bonus. They eventually collaborate with their peers and end up by participating in their own learning, achieving the set tasks as accurate as possible.

In the process both decision-making and problem solving come up as a result of collaborative search for more critical and creative responses that may better serve the purpose of the different groups of learners. Simultaneously learners improve their English skills, building up critical listening, reading, writing and speaking (illustrated further ahead).

Online English dictionaries inasmuch as reliable websites and background data sheets are used all through the project in order to develop ability to learn, to improve language learning, to undertake research into different domains, and to confirm and evaluate arguments and facts.

In general terms, learners mobilize their content-based knowledge, develop critical thinking and enhance English skills. The relevance of meaningful learning and in-depth knowledge [23] implies that students carry out new versions of their assignments, thinking and re-thinking, 
reformulating and completing them. At least one more version of their assignment is willingly done in most cases, as learners try to achieve a higher level concerning the different skills.

As noted before, learners evaluate their own performance using the self-regulation sheet, which includes learners' assessment. At this point, they engage in a metacognitive activity reflecting on the specific skills they have been using and the knowledge gained. They assess themselves in different levels regarding the different skills (L3, L2 or L1). Sometimes students tend to overestimate their own capacities and identify their level with their own self-interest, mainly at the very beginning of the project. However, when assessment is made in the threeelement group, and later with the supervising and mediator teacher, distorting biases and preconceptions are better perceived and fairness is restored. Actually, this is a principle included in the intellectual standards sheet provided to students, who are lead to understand that basic fair-mindedness, an essential feature of a critical thinker, may prove to be very difficult to achieve, requiring the constant exercise of disciplined thinking. Indeed, a belief consistent with Brand Blanchard axiom The main aim of education is practical and reflective judgement, a mind trained to be critical everywhere in the use of evidence [18].

As soon as their first version is done, one of the three-element group sheets is delivered to the teacher who provides feedback on the task without delay. The teacher discusses the work being undertaken, possible improvements to be made, and final assessments.

\section{ANALYSING INFORMATION}

Only after selecting one of the videos will learners analyse information, thinking analytically in order to understand the logic underlying the organization of ideas conveyed by the video. Activities, carried on in EFL, comprise identifying the main or central ideas in the video content, differentiating core ideas from supporting ones; finding a consecutive order in sequentially organised information and identifying stated or unstated purposes. As the assignment goes by, teachers notice that language learners, who tend to use the Portuguese language, make every effort to speak English in the three-element group. As a point of fact, collaborative learning helps students to feel more comfortable and keener on developing communicative strategies to cope with the demands of this language skill [7]. As Hegel, the German philosopher, puts it, to be aware of limitations is already to be beyond them (referred by Bassham et al. [18].

Although analysing information is a current and almost daily practice in English foreignlanguage lessons, a few $11^{\text {th }}$ graders still show problems regarding the differentiation of main ideas and supporting ones, and the organization of ideas in a logical sequence. Identifying unstated purposes proved to be rather more difficult than expected. Most of the times Socratic questioning is used to help learners to uncover unstated purposes.

\section{Connecting Information}

Learners are expected to relate the information being evaluated and analysed to new information that is significant in human life. Further still, they are to identify causal relationships between events related so far, predict possible consequences, and infer information. They continue building on their previous knowledge and mobilizing objective and subjective skills in a dynamic way, bearing in mind the universal intellectual standards. At this point of the project, not all students accomplish the tasks following its sequence as arranged in the selfregulation sheets. In point of fact, over half of the students seem not only capable of processing information as a whole but also to grasp how critical and creative thinking skills are essential components of language learning. Even so, reasoning backwards (identify causal connections that may have led to the problem and infer information) and forwards (thinking about possible 
consequences and predicting potential effects that may result from these problems) prove not to be tasks within easy reach for $11^{\text {th }}$ graders.

Aside from having been reorganizing their knowledge all along the practice, learners have also been creating knew knowledge by this time. In fact, just to take a few examples, they have summarised information, predicted possible effects, and related different subjects, mobilizing creative thinking skills that are closely tied to critical thinking skills.

From now on, students are expected to further develop creative thinking skills in an integrated and systematic process. This new knowledge is also analysed and evaluated using critical thinking skills, meaning that the relationship between critical and creative thinking is dynamic. From the five-set of self-regulation sheets, learners are now supposed to fill in two more sheets, dealing with major components of creative thinking: synthesising information, imagining processes and elaborating on information

\section{SYNTHESISING, IMAGINING, AND ELABORATING ON INFORMATION}

Bearing in mind the knowledge built on the information provided by the selected video, students are encouraged to generate original thoughts and ideas and devise a solution for the problem previously detected. Guided by the last two self-regulation sheets (create new knowledge), learners think about the video they are making, the new product to be published and shared on YouTube (a sheet designed to help foster the video making has been provided to students). Activities, carried out in EFL, comprise creating single analogies, like metaphors and similes to make information more understandable and appealing to the audience; predicting events related to the topic in discussion; speculating and wondering about interesting possibilities, asking hypothetical questions (what if questions); producing new ideas built on existing ones, expanding on information by adding details, examples or other information; planning the video creation scheme, including a step-by-step procedure to accomplish it; writing a video script (incorporating the knowledge constructed and synthesising ideas in learners' own words), and evaluating added information based critical thinking standards.

At this stage of the process some students prove to be capable of interrelating the tasks included in the last two sheets and accomplish them as a whole, showing that they are capable of solving problems creatively [39].

Until their scripts turn into movies, learners familiarize themselves with scripts' format, notation and length on trustworthy sources. The information collected so far, duly evaluated, is to be included into the script. Learners keep to the problem (s) identified (e.g. shopping addiction or mindless consumers) but the focus is now placed on the solution(s) provided.

Their role is now reversed. As scriptwriters (and producers), they assume a different point of view, engaging in higher-order writing and action-oriented processes. It is their role to take the audience to participate in the writer's dialogue and reason from it, to make meaning of the message they convey, to enter into the writer's view rather than their own, to make inferences and predictions, to identify implicit or explicit purposes, to understand connections made, to form opinions, to parallel experiences, to draw conclusions and amongst other aspects to raise consciousness of real-life problems.

While completely engaged in the process of drafting their scripts, the groups of learners loudly express their thinking, visualizing and imagining what the audience will be seeing and hearing. Taken by their creative vision, fluency of thinking, and the many ways of expressing ideas, they 
frequently have to impose constraint on themselves and rethink their plans so that thinking and writing gibberish is avoided as noted by Sharples [40]. Learners write and rewrite the script several times, until the final draft is suitable and new knowledge is created. Learners add and remove information, refine and enrich the content, try to show flashes of humour to delight the audience and to create suspense to stir the audience's emotions, beliefs and expectations.

Quite often, learners' scripts are incomplete in the sense that incompleteness is a desideratum in scripts [41], leading the audience to imagine, infer and predict information from wordsequence. However it also happens that some of the scripts are incomplete on behalf of learners who fail to merge all the information so far collected into a cohesive and coherent unit, leaving out important information and knowledge generated through their learning experience. On the other hand, a very few groups (about 10\%) write their scripts wiping out all the knowledge they have been constructing hitherto. It's not that they change categories by assuming a different point of view, it is just that they reason along very different lines and write a script with completely new information, not following the identified problem, the solutions devised, and the amount of information constructed and created.

As far as synthesising information is concerned, learners show great difficulties in thinking analogically, and merging all the information collected into a cohesive and coherent script. Predicting outcomes and hypothesising about relationships between events are also found difficult skills to develop because of their abstract nature.

\section{Phase One: Findings Critical And Creative Thinking}

A thorough analysis of the process calls for determining whether learners have developed their ability to learn, becoming independent and self-directed thinkers and learners, and whether they have improved the English foreign language (EFL), using the concepts and principles embedded in higher-order thinking (discussed further ahead in this study).

However, finding out whether reasoning processes development took place is crucial before addressing application and transfer of knowledge in the English foreign language. Students' assessments provide researchers with a broader perspective of the complexity involving the development of thinking processes.

Quantitative data was collected from the five-set of self-regulation sheets which include the assessment grids as aforesaid.

It is particularly important to clarify that cross-tabulations carried on within sub-sets of data have corroborated that those same learners who initiated the project in a given level are the very same learners who continue until the end of the project, regardless their progress or fluctuation between levels (i.e., the $1.2 \%$ of students who begin the project evaluating information are the same $1.2 \%$ who finish the project elaborating on information in what concerns level one; the $55.3 \%$ of students who begin the project evaluating information are the same $55.3 \%$ who finish the project elaborating on information in what concerns level two, and so forth). Tables 1 and 2 show the trends in skill development throughout the first phase of the project. 
Table 1. Trends in skilldevelopment at the beginning of the first phase

\begin{tabular}{|c|c|c|c|c|c|}
\hline \multirow{2}{*}{\multicolumn{2}{|c|}{$\begin{array}{c}\text { Critical and Creative } \\
\text { Thinking }\end{array}$}} & \multicolumn{3}{|c|}{ Analysing } & \multirow{2}{*}{ Total } \\
\hline & & Level 1 & Level 2 & Level 3 & \\
\hline \multirow{3}{*}{ Evaluating } & Level 1 & $1.2 \%$ & $0.0 \%$ & $0.0 \%$ & $1.2 \%$ \\
\hline & Level 2 & $0.0 \%$ & $49.4 \%$ & $5.9 \%$ & $55.3 \%$ \\
\hline & Level 3 & $0.0 \%$ & $4.7 \%$ & $38.8 \%$ & $43.5 \%$ \\
\hline \multicolumn{2}{|c|}{ Total } & $1,2 \%$ & $54,1 \%$ & $44,7 \%$ & $100.0 \%$ \\
\hline
\end{tabular}

Table 2. Trends in skill development at the end of the first phase

\begin{tabular}{|c|c|c|c|c|c|}
\hline \multirow{2}{*}{\multicolumn{2}{|c|}{$\begin{array}{c}\text { Critical and Creative } \\
\text { Thinking }\end{array}$}} & \multicolumn{3}{|c|}{ Elaborating } & \multirow{2}{*}{ Total } \\
\hline & & Level 1 & Level 2 & Level 3 & \\
\hline \multirow{3}{*}{ Evaluating } & Level 1 & $0.0 \%$ & $1.2 \%$ & $0.0 \%$ & $1.2 \%$ \\
\hline & Level 2 & $0.0 \%$ & $37.6 \%$ & $17.7 \%$ & $55.3 \%$ \\
\hline & Level 3 & $0.0 \%$ & $24.7 \%$ & $18.8 \%$ & $43.5 \%$ \\
\hline \multicolumn{2}{|c|}{ Total } & $0.0 \%$ & $63.5 \%$ & $36.5 \%$ & $100.0 \%$ \\
\hline
\end{tabular}

Findings show that by the end of the first phase of the project, level-one learners advanced their reasoning skills from level one (Table 1) to level two (Table 2). Intermediate learners' level rose by $11.8 \%$ from level 2 (Table 1 ) to level 3 (Table 2 ).

On the other hand, a quite wide fluctuation was found between intermediate and advanced levels when examining trend changes in skill development. Level fluctuations had to do with the difficulties learners experienced in developing the different thinking strategies, and accordingly assessing themselves in a lower or a higher level. As a matter of fact, as noted before, if evaluating information was found to be a hard skill for students to develop, all the ensuing skills entailed challenge, intellectual disposition and skilled judgement, mainly some creative thinking skills which were not as objective and easily developed as other skills [22]. Actually, developing mental processes proved to be highly complex [21]. The majority of learners found it difficult and effortful, as the cognitive demands for solving the tasks involved substantial mental work.

Considering the increasing difficulty in skill development, it seems there has been a gradual advance and therefore a positive outcome of level one and level two learners throughout this first phase of the project. As for level three graders, achievement of the most advanced level or maintenance of level two (intermediate level) at the end of the first phase of the project might be regarded as a success. In fact, learners were able to overcome the increasing thinking complexity and accomplish their purpose of building up mental processes.

\section{Language Learning}

As previously highlighted, the process aims to examine whether learners have developed their ability to learn, becoming independent and self-directed thinkers and learners, and whether they have improved the English foreign language (EFL), in particular Speaking (spoken production and interaction), applying higher-order thinking principles, which were explicitly developed within explicit subject content.

Learners who initiated the project in a given level keep the very same learners until the end of the project (as mentioned above). 
Table 3 shows the trends in the development of EFL Speaking skills throughout the first phase of the project.

Table 3. EFL Speaking skill development at the beginning of the first phase

\begin{tabular}{|c|c|c|c|c|c|}
\hline \multirow{2}{*}{\multicolumn{2}{|c|}{$\begin{array}{l}\text { EFL Speaking } \\
\text { Skills }\end{array}$}} & \multicolumn{3}{|c|}{ Analysing } & \multirow{2}{*}{ Total } \\
\hline & & Level 1 & Level 2 & Level 3 & \\
\hline \multirow{3}{*}{ Evaluating } & $\begin{array}{c}\text { Level } \\
1\end{array}$ & $19 \%$ & $8 \%$ & $0 \%$ & $27 \%$ \\
\hline & $\begin{array}{l}\text { Level } \\
2\end{array}$ & $0 \%$ & $71 \%$ & $1 \%$ & $72 \%$ \\
\hline & $\begin{array}{c}\text { Level } \\
3\end{array}$ & $0 \%$ & $0 \%$ & $1 \%$ & $1 \%$ \\
\hline \multicolumn{2}{|c|}{ Total } & $19 \%$ & $79 \%$ & $2 \%$ & $100 \%$ \\
\hline
\end{tabular}

Table 4. EFL Speaking skill development at the end of the first phase

\begin{tabular}{|cc|ccc|c|}
\hline \multirow{2}{*}{ EFL Speaking Skills } & \multicolumn{3}{|c|}{ Elaborating } & \multirow{2}{*}{ Total } \\
& Level 1 & Level 2 & Level 3 & \\
\hline \multirow{3}{*}{ Evaluating } & $16.5 \%$ & $10.6 \%$ & $0.0 \%$ & $27.1 \%$ \\
& Level 2 & $0.0 \%$ & $62.3 \%$ & $9.4 \%$ & $71.7 \%$ \\
& Level 3 & $0.0 \%$ & $0.0 \%$ & $1.2 \%$ & $1.2 \%$ \\
\hline \multicolumn{2}{|c|}{ Total } & $16.5 \%$ & $72.9 \%$ & $10.6 \%$ & $100 \%$ \\
\hline
\end{tabular}

Examining trends in EFL Speaking skill development, a gradual upward tendency was found in the first phase of the project, continuing along it. Table 2 shows that $2.6 \%$ of low-level learners have edged up to the intermediate level and two learners have edged up to the advanced level all through the first phase. A ratio of $16.5 \%$ in a total of 85 students remained in level one. These results show that language learning was benefited by the continuous cognitive efforts demanded by thinking strategies development. Bearing in mind the increasing complexity of thinking processes, the slight improvement is a positive outcome. In general, while developing in-depth learning through content, learners improved pre-existing linguistic, sociolinguistic and pragmatic competences. Little by little, learners grasped and consciously applied intellectual tools and universal intellectual standards to higher-order speaking and listening.

Actually, real problems and beliefs conveyed by YouTube anonymous youths or adults appear to have actively engaged learners, who listened repeatedly and attentively to the speakers' words. While looking for relevant, clear, consistent, and complete video examples, learners tried to enter sympathetically into the speakers' perspective, discussing alternative interpretations and different points of view both from the speaker and the group peers, accepting and rejecting explanations provided and reasoning from everyone's views. For example, forum participants explained, finding the most appropriate video was not an easy task as the three of us had to share the points of view of the author of the video and support them "; "we were not only dealing with our own differences but also with the author's ... discussing different ideas allowed us to go further.

Clear examples of learners' effort to improve the linguistic competence might be the active use both of new words and phrases taken from authentic language used in the different social settings (lexical competence), and of grammatical structures taken from the authentic discourse conveyed by the speakers (grammatical and orthography competence). The 
development of their ability to better pronounce English words by listening attentively to the authentic spoken utterances (phonological and orthography competence) was also noticed.

Low-level learners tended to interact in English briefly both in the three-element group and with the class and the teacher, starting with short sentences consisting of a single clause, but as time went by there was a growing effort to use the foreign language for longer periods of time, finishing with simple co-ordinate and subordinate clauses (grammatical competence/syntax). To cope with the communicative demands placed upon them, they also developed discourse strategies such as requesting clarification, checking for confirmation, trying to work out some kind of meaning on the basis of the few structures they knew, and using English or bilingual dictionaries online. Recalling trends in skill development, the $1.2 \%$ edge of level-one students, suggests that the foreign language has not been a hindrance to skill development. Actually, they persevered with their tasks, showing creativity, capacity to solve problems and make decisions, and ability to continue to develop their language skills autonomously.

As for intermediate and advanced language achievers, there was good evidence of the linguistic and pragmatic demands for task accomplishment. While explicitly developing their ability to analyse new knowledge, to elaborate on new information, to write creative scripts regarding controversial issues, and to play different roles, learners were also developing their control over grammar, vocabulary, phonology and orthography. Indeed, both language resources such as range, grammatical and lexical accuracy, and aspects of language such as fluency, flexibility, coherence, appropriateness and precision were developed through the whole approach.

\section{Phase Two: Applying The Knowledge Gained Video Production}

Following the script writing and all the steps it entails, learners finally undertake the film production. It is rewarding to appreciate how learners' finally accomplish what they have set out to do. The video production gives them a reason to every effort made and encouraged them to cooperate, to interact, to persevere and to actively represent their knowledge.

Clear evidence of Theodosakis' words [24] is also provided as the five-minute video production demands focus. Some students have to change the plans made and reorganise their scripts' information. Editing the video requires constant problem solving, further analysis of facts and details, and re-evaluation based on rigorous standards of thought. The designing process, demands a lot of design problem solving and continuous decision-making processes, since it entails cutting and pasting small pieces of movies, the use of photos, drawings, music, the use of transitions, and the processes of realigning, reassembling, fitting, colour, rhythm, fluidity, and expansion [42].

Finally, oral presentations of the created videos are made to the class in the foreign language. The different groups of learners are believed to have carefully planned their video delivery so that it may be effective. Firstly whole watching of the video is the learners' suggested approach. The second viewing is used as scaffolding material into speaking practice, oral presentation skills, and critical discussions conduct. Students stop and review the video so that the group of students together with the class and the teacher can critically and creatively discuss and debate the issues addressed. The group takes notes of suggestions provided in order to improve their videos. Finally they make their self-assessment concerning both the video making and speaking skills (spoken production and interaction). The three-element groups evaluate their peers' videos as well. Assessments are then discussed and compared to the teacher's and a consensus is built on the final mark of each student. 
A last version of the video is later presented to the class again.

The videos are then uploaded and shared on YouTube (most of the times more than one version is published since they are improved over time; the number of views is larger in the first post of the video since the novelty wears off). Students write a short description, indicating their category and the topic. Some students interact with YouTube users sharing social knowledge online. Comments made on the videos published by learners appear only in the first uploads.

Unfortunately, some parents do not allow their teenage children to post videos that portray them as movie characters. Some of the previous years' examples are also called up as evidence of the running project over the years.

The videos are currently on view at YouTube:

- The story of a shopaholic Consumer Society

- http://www.youtube.com/watch?v=Dhrj-n6f22c\&feature=youtu.be

- Consumer Society

- http://www.youtube.com/watch?v=0SB9TAmL6tY\&feature=youtu.be

- Be yourself finding against discrimination

- http://www.youtube.com/watch?v=MahidmNruA8\&feature=watch_response

- Racism: a one-way road

- http://www.youtube.com/watch?v=aC5JMye1w6g

\section{Phase Two: Findings Development Of Processes Oriented To Action}

The videos published and shared on YouTube come up as good evidence of learners' gains and prowess in representing meaningful real-world problems critically and creatively. Their creative and practical solutions, or the audience sensitization to serious problems, suggest they were able to deal with problem solving.

Learners' gains were found highly significant since $79 \%$ of learners were successfully able to apply the knowledge and the reasoning abilities gained into the production of their own videos being scored in level three. The remaining 21\% of learners showed some difficulty in accomplishing their purposes, being scored in the intermediate level. In some cases, their preoccupation with the final product, giving more value to technical aspects than to the process, has hampered them to deepen the subject matter to be represented. Instability in a few groups and poor language command also seem to have contributed to a growing intellectual laziness and conformism to group standards of judgement, disabling a few learners of decision-making. However, learners showed a great strength of purpose and made a second, third or even a fourth version of the video to accomplish their purpose. Main problems were related to provide well-supported arguments, to think analogically, to make inferences, to hypothesise about relationships between events and predicting outcomes, to foreign language command, and commitment to intellectual standards (clarity, consistency, precision and logical correctness).

\section{Technological Tools' Evaluation}

As envisaged by Siemens [14] and Tapscott [3] the relationship between teachers and students in the classroom has changed, specifically in the video production phase. Actually, learners took centre stage all through the process [9], but in the technologies domain, they took a 
leadership role; learners became the teachers and the teachers became the students. Teachers respected learners as the empowered authorities and sometimes learned with them. This reciprocity created a more friendly, consensual and effective relationship between learners and teachers in the classroom.

All along the project, learners had to solve multiple complex problems and take decisive action on the best way to represent their knowledge, collaborating and cooperating with each other while using cognitive tools critically, creatively, skilfully and confidently.

In the second phase of the project, learners immersed themselves into innovative and creative production environments, showing their easiness and confidence to represent the knowledge they had critically and creatively constructed with the support and help of YouTube videos in the first phase of the project. Learners evaluated and selected feature-rich software programs with a critical eye, predicting the problems they would have to face over the designing phase. Creative programs just like Sony Vegas and Camtasia were combined with editing programs and animation techniques like Adobe Photoshop, and Stop Motion. As part of an integrated and systematic process, these interactive and cognitive tools provided an empathic and supportive environment, which stimulated and engaged learners in meaningful learning, fostering higherorder thinking processes, and language learning as put by Duffy and Cunningham [25] and Toro [26].

As intellectual partners the selected tools contributed to in-depth learning and facilitated the meaning-making process to most learners. Hadn't learners thought deeply about the content they were representing, tools wouldn't have been used so skilfully and creatively. Most learners willingly repeated the process as many times as needed in order to accomplish their purpose. Until the video took form, information was restructured, different parts of the film were rearranged and connected, and random problems concerning the proper use of the software were solved on time. Forum participants explained that problems with software took us some time because some programs weren't good enough, we had to choose different ones that met our needs, and still we had to acquire the extensive editing skills required to operate that software (A. $\left.11^{\circ} \mathrm{N}\right)$ "; "the script was too long and not all parts of it worked in the video, deciding which parts of our script should be excluded was a very difficult task (D. 11을.

As for the last phase of the project, learners showed their intellectual empathy with tools which call for thinking in non-linear ways, choosing demanding and creative tools (just like Prezi) to present their assignments on The Freedom Writers' Diary [34].

\section{Language Learning}

Learners' capacity to learn and improve the English language was easier to notice when applying their reasoning skills in the second phase of the process, which provided a rich linguistic environment for active participation in communicative interaction, a necessary condition for language development [7]. Actually, learners from all levels got involved in the interactive process, discussing the video production animatedly. As learners were pasting small pieces of movies, realigning, reassembling, fitting colour, rhythm, fluidity and expansion [42] they were communicating spontaneously either explaining main points in ideas with reasonable precision (level-three learners), or giving reasons and explanations for their opinions and plans (level-two learners), or still exchanging ideas briefly (level-one learners).

The presentation of the videos made by the different groups to the whole class, and further analysis of transcripts of these presentations, showed how critical and creative thinking based 
on intellectual standards was applied in communicative action. Development of pragmatic and sociolinguistic competence was observed in the increasing complexity of their discourse, the wider functional range, the adherence to verbal exchange patterns, the aware-raising (analysis, explanation, terminology), and the attention drawn to sociolinguistic contrasts, the error analysis and correct usage. The different groups of learners presenting the video conducted critical discussions with their peers and the teacher with relative ease, as the topics under discussion were familiar to all members of the group. Among other aspects, they discussed the purpose of the videos and its clarity, relevance and fairness of the problem(s) addressed in the videos, solution(s) provided for problem(s), connections made between the main problem and other problems, the significance of these subjects/problems in human life, assumptions made, reasons or evidence upon which claims were based, possible answers to what if questions asked in the videos, possible inferences, implications and consequences that followed from learners' reasoning, conclusions drawn, commitment to intellectual standards, use of humour, suspense and other techniques, reliability of sources, and value of technological tools used as cognitive tools.

Respecting accuracy and fluency, level-three learners showed a high degree of grammatical control. If any mistake was made it was carefully corrected so that no misunderstanding could be caused. Level-two students discussed aspects associated with predictable situations reasonably accurate. They thoughtfully paused for grammatical and lexical repair in longer stretches of free production and interaction to make discourse comprehensible to their peers. Level-one learners presented the simplest aspects using simple structures correctly. Despite the mistakes, they made themselves understand, carefully evaluating and reformulating their ideas.

Results suggest that learners developed their heuristic skills and ability to learn, particularly relevant in language learning [7], and that they were able to apply thinking principles and underlying intellectual standards in communicative situations that constantly required problem solving and decision-making.

Figures show that a ratio of $14 \%$ in a total of 85 learners were found to be in level one, $68.2 \%$ in the intermediate level, and $17.8 \%$ in the higher level. Final language achievements will be made and discussed further ahead.

\section{Phase Three: Transfer Of Knowledge Description And Findings}

Despite being a debatable issue, some authors believe that transfer of knowledge and skills to other contexts is possible particularly if learners are given opportunities to practise the skills gained in authentic learning activities that represent real-world problems, and if they are specifically taught to transfer the skills [43], [44]. McPeck [45] also finds that the transfer of critical thinking skills and abilities to real-world contexts is possible, particularly when developed in authentic learning environments that represent everyday life problems.

The goal of the following task was to assess transfer of newly acquired thinking processes, which were learned in the context of EFL controversial consumerism issues taken from YouTube videos, into a new EFL context - American teenagers' multicultural dilemmas - and from this to a new one - Portuguese learners' everyday life problems.

Throughout the school year, learners had been reading the non-fiction 1999 book The Freedom Writers Diary related to one of the socio-scientific content areas The Multicultural World to be studied in the $11^{\text {th }}$ grade. The diaries have been written by an American diverse group of at- 
risk students who were embroiled in the racial gang war culture of the time. Some diaries had been analysed in class before the research action project has taken place.

The individual tasks consisted of selecting a diary from the book, and identifying real-world problems, which demanded entering sympathetically and analytically into an inner dialogue with the writer. Learners had then to present the diary to the class, conducting critical and creative discussions with classmates, always focussing on finding possible solutions to the acknowledged complex problems.

The assignment demanded an active participation of each one of the learners in the process of reading, listening, and speaking in the English language.

Higher-order reading and analogical thinking were shown straightaway from all learners who showed to be capable of reading, evaluating and selecting diaries which dealt with controversial issues set in a very different context. Even though American teenagers' problems were quite different and sometimes unfamiliar, learners always found themselves within the pages of the book. Clear examples were: fitting in at school (diary 17); being the target of others' manipulation (diary 33); female molesting (diary 39); double standards for men and women (diary 61); alcoholic stepdads (diary 64); discrimination based on learning disabilities (d.70); dream career (diary 104); coward fathers (diary 110); loss of a mother (diary 113); letting evil prevail by watching and doing nothing (diary 119); being a lesbian (diary 127); early pregnancy (diary 135).

Learners have shown their grasp of the standards of higher-order thinking by analysing and interpreting the selected diaries insightfully. They actively looked for the writers' point of view and purpose (resisting their bias), core ideas and supporting ones, reasons and justifications, causal and consequential relationships, grounding conclusions, literary devices (analogies, metaphors, similes) and other structural features thanks to the principles of critical and creative thinking I was able to read and understand the diaries (mine and all the others) in a completely different perspective. Feeling how the freedom writer felt when he wrote the diary and being capable of reading "between the lines" was essential to do my assignment (A.L. 11으); I started by questioning the writer's actions, the reason that made him write, I speculated on possible causes ... (R.11ํN).

Presentation of the diary to the class demanded higher-order speaking and listening.

Learners showed they were able to debate controversial subjects and to parallel experiences, applying the knowledge and principles gained and transferring it into new contexts. Subjects were transferred from The Freedom Writers' problems (a) into other subject-related problems (b) and all these to personal experience (c). To take just some examples, problems paralleled and opened to discussion were:

(a) alcoholic stepdads (The Freedom Writers' problem, diary 64) / (b) dysfunctional families (the other subject-related problem) / (c) my mother's purple eyes (personal experience subject);

(a) being the target of others' manipulation (diary 33) / (b) being racked with the guilt one has inside / (c) take the lead to help others;
(a) dream career
(diary 104)
(b) Portugusese
financial crisis
(c) my ideal job/unemployment; 
(a) being a lesbian (diary 127) / (b) tolerance / c) sexual orientation / discrimination;
(a) early pregnancy (diary
15) /
(b) abortion / c) overcoming adversity.

In their 30/40-minute presentation, besides paralleling these subjects, learners compared and contrasted information based on other books and diaries (e.g., The Diary of Anne Frank, and Zlata's Diary: A Child's life in Sarajevo), poetry (e.g., Barbara Sonek Holocaust), photographs (Nandor Glid's International Monument), and short extracts of films (e.g., Colour Purple), which helped to better learners' discourse, and to bring knowledge and others' beliefs to life.

As expected, transfer of knowledge and principles embedded in higher-order thinking was most clearly evidenced in high level and intermediate students due to their better command of EFL.

The complexity of the issues and questions posed by high level and intermediate students suggested they had learned to think for themselves based on evidence rather than on unwarranted assumptions. Evidence of transfer from the writers' context to learners' own context was shown. Learners paralleled the writers' and their thinking, thinking the thinking of the author, working the author's ideas into their thinking and discussing those thoughts with classmates in their own words. They seemed to be able to put themselves in the writers' and their peers' place, questioning and thinking while listening to classmates, considering alternative interpretations and different points of view, accepting and analysing explanations provided and trying to form judgements after considering all facts. On the other hand, they showed to be capable of asking vital questions often calling for different modes of thinking (particularly regarding solutions for the problems lively debated), to ask and give justifications of opinions, illustrating their ideas with their own examples, and to use arguments based on reliable knowledge, life experiences and beliefs. A reasonable command of intellectual standards was apparent. Learners stayed focussed on relevant ideas, discussed issues with an open mind as much thoroughly as possible, tried to express themselves clearly and accurately (using their own words, examples and illustrations, giving attention to word usages and their implications, and paying close attention to literary devices and other structural text features), indicated reliable sources, insisted on precise answers, and called peers' attention to inconsistencies in their thinking and arguments. Interesting points were made by participants on the forum: urging classmates' creativity to bring about different solutions to the problems we were debating was pretty challenging (A.I.11으); we looked at problems from a fresh and more innovative way, debating, accepting, dismissing unfounded opinions, and using several peers' ideas for developing other ideas (A.C.11N) ; I wasn't expecting to hear so many different points of view and debate them all...it seemed the discussions were never going to end (anonymous).

As for level-one learners' ability, responsibility for their own learning and confidence-building feedback helped to increase their ability to interact with peers and conduct short discussions around the dilemmas selected in this phase of the project. Learners seem to have improved significantly their capacity to think and read critically, connecting what they read to their life, showing their ability to pose creative questions in their own words, to speculate (asking what if questions), to summarize main points, and to formulate simple arguments.

All in all, defending their claims with reasons, bringing about facts to support their points, and reasoning from their beliefs to conclusions proved to be one of the most difficult tasks to all learners. 
Following the line of thought of Anderson et al. [44], all learners were found to have significantly improved thinking processes as observed in new formal contexts and informal ones, indicating transfer of knowledge and thinking processes across domains. Actually, learners proved capable of transferring the thinking principles and knowledge gained in EFL YouTube context into everyday life contexts [45], and pointing out new solutions to complex problems they are faced with My Philosophy teacher said it was clear that we, the class, had

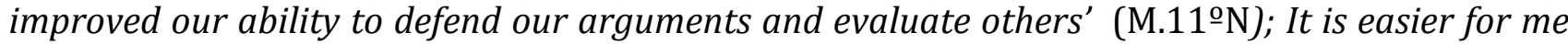
now to understand and relate the issues discussed in the various subjects and classes (R.11-F); In our relationships, we many times have to infer what others are thinking and feeling in order to keep a healthy relation. I think that learning about Critical and Creative Thinking helped me, for instance to understand how my friends or family are and to find out creative ways to support

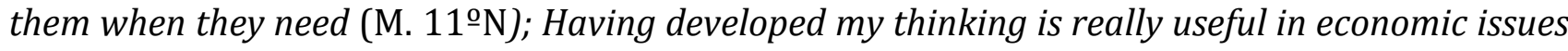
because it helps me, for instance, to analyse critically how I spend my money, wonder if I really need to, find out creative ways to save money without losing quality of life and to speculate, for example, about what may happen to Portuguese finances in the future in order to take the right decisions now, specially those relative to my future career (M.11ㅇN).

Most importantly, students showed their intellectual humility before serious problems other teenagers face in their everyday life, and learned to concentrate their efforts on finding solutions for different dilemmas rather than focussing on the problems Besides being engaged with problems everyone should worry about, this project helped to develop our capacity to think of solutions for different problems, to fight for greater purposes, and therefore to be better people $\left(\mathrm{I} .11^{\circ} \mathrm{N}\right)$.

Being capable of reflecting on others' and their own judgements and make sensible decisions was another aspect mentioned by forum participants: We many times accept what others say without even questioning it and I feel that after working on the Thinking Project at school, I started to think more critically on what others say and then decide if I accept it or not (A.P.11으).

\section{Language Learning Findinds At The End of The Process}

Once the research is complete, findings concerning EFL Speaking accomplishments in the third phase of the approach are compared to the first and second phases' as illustrated below.

\begin{tabular}{|ccccc|}
\hline $\begin{array}{c}\text { EFL } \\
\text { Speaking }\end{array}$ & $\begin{array}{c}\text { 1st phase } \\
\text { (beginning) }\end{array}$ & $\begin{array}{c}\text { 1st } \\
\text { phase } \\
\text { (end) }\end{array}$ & $\begin{array}{c}\mathbf{2}^{\text {nd }} \\
\text { phase }\end{array}$ & $\begin{array}{c}\mathbf{3}^{\text {rd }} \\
\text { phase }\end{array}$ \\
Level 1 & $19 \%$ & $16.5 \%$ & $14 \%$ & $9 \%$ \\
Level 2 & $79 \%$ & $72.9 \%$ & $68.2 \%$ & $61.3 \%$ \\
Level 3 & $2 \%$ & $10.6 \%$ & $17.8 \%$ & $29.7 \%$ \\
\hline
\end{tabular}

Table 5. EFL speaking accomplishments throughout the project

Figures presented in Table 5 show the advances made in EFL Speaking skills from the first to the last phase of the project. Differences between the beginning and the end of the process were statistically significant in all three levels, even though progress was most clearly evidenced in the intermediate and high-level learners' results. While intermediate and highlevel learners increased $17.7 \%$ and $27.7 \%$ respectively, low-level learners increased their ability by $10 \%$. Once it is recognized that language learning is a life long task [7], the steady gains among the three levels may be considered significant as students' awakening to higherorder language skills comes to be of central importance. As mentioned earlier these results reflect learners' grasping of higher-order thinking principles, which were developed interdependently and systemically. 
It is to be noted that though ten per cent of learners have not edged up their speaking skill level, it does not mean that they have not developed thinking strategies. As previously highlighted, all level-one students edged up to the intermediate level concerning skill development, suggesting that the project has contributed to develop their reasoning capacities, thinking independence and ability to continue to develop their language skills autonomously. As a matter of fact, third-phase individual assignments were further proof of their self-directed thinking and learning.

Also important is the development of learners' personality provided, over time, by language interaction in the forum and in the class: discussions in the group, about the English videos we were selecting, were very interesting, and my peers' way of thinking and experiences gave me different perspectives on life (anonymous). The various views of my classmates sometimes made me think over my beliefs, and sometimes change my mind (A.P.11으).

\section{Future Research Directions}

The development of the ability to think actively and logically, associated to the development of both digital and communicative skills is considered of paramount importance in educational environments as contemplated in strategic European documents [1], [2]. The present study which may be approached in a wide variety of subjects, contexts, and educational levels comes up as a first step to help learners get the knowledge and skills they will need in the competitive knowledge economy. Its findings and conclusions sustain educational significance for teacher development in the context of projects that involve fostering thinking skills through content and technology-based tools in language classrooms so as to enhance students' learning and ability to learn. Considering the continuous learning nature, the researchers believe it would be appropriate to implement the approach earlier, in elementary school (9-year-old students onward) in a didactic framework suitable to this level of education. The researchers have already begun to structure professional development regarding this educational level, focussing it on practical tools such as the ones described in the project (including worksheets), for helping learners and teachers meet the $21^{\text {st }}$ century needs.

\section{CONCLUSIONS}

The first objective of our study was to investigate the effectiveness of explicit development of higher-order thinking on EFL learning. Findings showed that the explicit development of higher-order thinking processes based on real and meaningful world problems was appropriate and effective regarding the improvement of EFL skills particularly on Speaking, the focus of our study.

By the end of the first phase, findings indicated that a gradual upward tendency was found in the EFL Speaking skill (table 3 and table 4), continuing all along the practice. Placing an explicit emphasis on the development of critical and creative thinking principles, and universal intellectual standards, while simultaneously articulating them with language learning, helped leaners to be aware of the highly significant impact of those principles on the improvement of pre-existing linguistic, sociolinguistic and pragmatic competences. Second and third-phase data clearly showed students' grasp of the process as they were able to restructure the information in meaning and usable ways, indicating that language has been learnt as a form of thinking [23]. In point of fact, not only were they capable of investigating, evaluating, analysing, connecting, reflecting and questioning about real-world problems but also to generate new knowledge, assuming different views as scriptwriters, and presenting creative solutions [39], while engaging in higher-order writing, speaking and action-oriented processes. These results support previous findings that show students' critical thinking gains as a consequence of an 
explicit approach integrated in the subject-matter content of the discipline [20], [36], [37]. However, it is worth noting that, given learners' characteristics, such as their need for immediacy, multitasking, and fluency of ideas [3], [40], the great majority of learners would have preferred to develop reasoning processes and make their video simultaneously [24] rather than develop thinking strategies gradually in a first stage of the process (mentioned by participants on the forum). Nonetheless, recalling students' diagnosed problems using the elements of reasoning in accordance with appropriate intellectual standards [30], it became apparent that learners first needed to learn to use their minds and think for themselves, developing mental processes step-by-step, and only then create new products, practicing and applying the knowledge and skills gained. As a matter of fact, as the process was unfolding explicitly, learners were consciously and better relating the subjects being studied in EFL to other subjects and to meaningful and real life situations and thus making sense of what they were learning [23].

Concerning the second purpose - the effectiveness of cognitive tools on the process- learners' empowerment and confidence in the technologies domain fostered greater autonomy, independent thinking and self-discipline over the different phases of the process. As witnessed by all teachers, YouTube videos worked as intellectual partners, requiring learners to think harder about the subject matter being studied and represented [23]. As part of the integrated and systematic process, they provided an emphatic environment [3], [14], they engaged learners in cognitive operations like fostering multiple skills of critical thinking [24], and language learning [25], [26]. All along the project, learners proved to be able to solve multiple complex problems, and to make intelligent decisions about what to do, specifically take decisive action on the most appropriate and creative tools to better represent meaningful realworld problems creatively, critically, and skilfully.

The third objective of the study was to investigate whether learners effectively apply and transfer the knowledge newly gained into different learning contexts, and ultimately in daily life situations, accomplishing larger action-oriented processes.

Results showed major differences regarding learners' achievements, indicating that an improvement was found in learners' reasoning abilities, learners' EFL ability, and learners' ability to apply and transfer acquired knowledge into a different learning context and ultimately into everyday life situations, solving problems and making decisions intelligently. To be precise, first-phase data showed that there was a gradual advance of all learners regarding the building up of mental processes and foreign language learning in the context of Teens and the Consumer Society. Second-phase data indicated that the great majority of learners were successfully able to apply and further reasoning abilities and language competence in the same EFL context Teens and the Consumer Society.

Third-phase findings provided possible evidence to affirm that the goal of transfer was achieved. Being part of a joint learning system, the approach was designed to provide students with opportunities to practise and further the skills gained in authentic learning activities that represented real-world problems, allowing them to learn and be able to transfer the skills to unfamiliar situations within the same domain and to everyday life problems learners. In fact, the developmental process may have impacted their ability to transfer the knowledge to different contexts [43], [44], [45]. However, although students continued to practise transfer of higher-order principles governing communication skills (as mentioned earlier), it would be important to examine learners' ability to transfer the knowledge gained in a EFL context into other disciplines after a period of time. 
It also follows that, applying and transferring the knowledge and skills within other situations, including into their everyday life definitely intensified learners' awareness of their personal enrichment not only in terms of language learning but also in terms of identity, motivations, attitudes, beliefs and heuristic skills. Learners accomplished larger processes oriented to action, in particular applying higher-order principles and intellectual standards in communicative situations involving problem solving and decision-making. Despite the high complexity and substantial mental work required by the process, emotions may have played an important role in the process [12], [13], [14], as learners showed intellectual disposition needed to accomplish their purpose of building up higher-order processes [18]. Learners actively involved themselves with the selected issues, collaborating and cooperating with their peers in the building of meaningful knowledge, and learning to build consensus, and potentially achieving higher levels of thought [6], [23], [31]. A progressive transfer of responsibility for their own learning was noticeable, as students continuously reflected on their successes and failures, showing to be able to take apart their thinking and examine the elements for quality [46]. Furthermore, learners' active participation in the new approach [9], [14] raised their awareness of new learning processes, allowing them to recognize their cognitive style and develop their own learning strategies accordingly, becoming independent and self-directed thinkers and learners [18].

Figure 4 illustrates the three-dimensional project centred on the development of larger processes oriented to action.

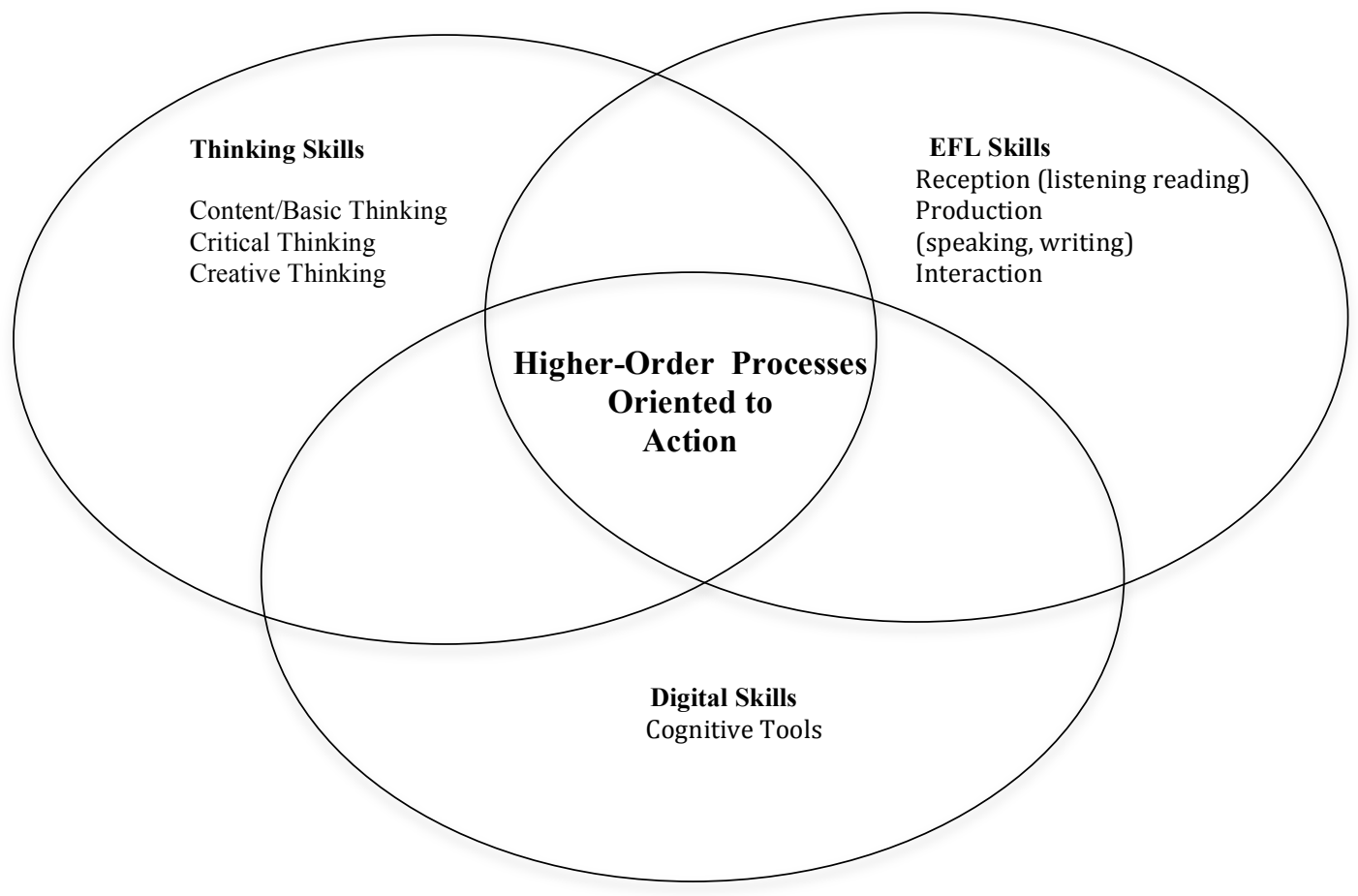

Figure 1. The Three-Dimensional Process

The approach worked like a Venn diagram comprising overlapping skills: language skills (EFL), thinking skills and digital skills. Finding the three-set centre, the point at which skills intersect with larger action-oriented processes, proved to be attainable for learners. 


\section{Acknowledgements}

The authors wish to thank to EFL teachers and all the students who took part in the project described. This work is supported by CIED (Center for Research in Education) by FCT funds (for Science and Technology), under the PEST - OE project / CED / UI 1661/2014

\section{References}

European Commission. "Recommendation of the European Parliament and the Council of 18 december 2006 on key competences for life long learning," Off. J. Eur. Union, pp. 394-404, 2006.

European Comission. "Information and Communication Technologies.'ICT Work Programme 2013."” 2011.

D. Tapscott. Grown up digital: how the net generation is changing your world. New York, USA: McGraw-Hill, 2009.

D. Oblinger. Boomers, Gen-Xers, Millennials: Understanding the new students. EDUCAUSE Review, 38(4), 37-47, 2003.

G. Siemens. "Connectivism - A learning theory for the digital age," Int. J. Instr. Tecnol. Distance Learn., vol. 2, 2005.

R. Paul and L. Elder. Critical Thinking: Tools for Taking Charge of Your Professional and Personal Life, 2nd ed. New Jersey, USA: Pearson, 2014.

Council of Europe. Common European Framework of Reference for Languages : Learning, Teaching, Assessment. Cambridge, England. Cambridge University Press, 2001.

J. Gordon, G. Halasz, M. Krawczyk, A. Michel, E. Putkiewicz, and J. Wisniewski. "Key Competences in Europe: Opening Doors for Lifelong Learners Across the School Curriculum and Teacher Education," Warsaw, Poland, 2009.

C. Coll, E. Martin, T. Mauri. O construtivismo na sala de aula. S. Paulo, Brasil: Ática, 2006.

D. P. Ausubel. Educational psychology: A cognitive view. New York: Holt, Rinehart and Winston Inc., 1968.

J. Bruner. The process of education. Harvard University Press, 1999.

A. Damásio. O Erro de Descartes - Emoção, Razão e Cérebro Humano. Publicações Europa-América Lda., 1998.

M. Lipman. Thinking in Education, 2nd ed. UK, Cambridge: University Press, 2003.

G. Siemens. Knowing knowledge. Raleigh, North Carolina,USA: Lulu.com, 2006.

H. Gardner. Multiple intelligences. The theory in practice. New York, USA: Basic Books, 1993.

J. M. Paraskeva and L. R. Oliveira. "Teoria Crítica, Currículo e Tecnologia Educativa," in Currículo e Tecnologia Educativa, vol. 2, no. Pedago, J. M. Paraskeva and L. R. Oliveira, Eds. Mangualde, Portugal: Pedago, 2008, pp. 7-17.

M. Llosa. La civilización del espectáculo. Santillana Editiones Generales, 2012.

G. Bassham, W. Irwin, H. Nardone, and J. M. Wallace. Critical thinking: A student's introduction. New York, USA: McGraw-Hill, 2005.

P.Airasian, K.Cruikshank, R. Mayer, P.Pintrich, J.Raths, and M. Wittrock. A Taxonomy for Learning, Teaching, and Assessing: A Revision of Bloom's Taxonomy of Educational Objectives, 2nd ed. Boston, MA: Pearson, 2001.

R. H. Ennis. "Critical thinking and subject specificity: Clarification and needed research," Educ. Res., vol. 18, no. 3, pp. 4-10, 1989.

L. Resnick. Education and learning to think. Washington, DC, USA: National Academy Press, 1987.

D. H. Jonassen. Computers in the classroom - Mind Tools for Critical Thinking. Hillsdale, NJ, USA: Prentice Hall, 1996.

D. H. Jonassen. Computadores, Ferramentas Cognitivas_ Desenvolver o Pensamento Crítico nas Escolas. Tradução: Gonçalves A. R. , Fradão, F. \& Soares, M. F. (2ª edição). Porto Editora, 2007

N. Theodosakis. The Director in the Classroom - How Filmmaking Inspires Learning, 2nd ed. British Columbia, Canada: Pentiction, 2009.

T. D. Duffy, \& D.J. Cunningham. Constructivism: Implications for the design and delivery of instruction. In D. H. Jonassen, (Ed.). Handbook of research on educational communications and technology: A project of the association for educational communications and technology. New York: Macmillan, 1996. 
M.A. Toro. The Effects of HyperCard Authoring on Computer-Related Atittudes and Spanish Language Acquisition. Computers in Human Behaviour. Vol 11 (3), pp-663-647. Elsevier Science Limited. USA, 1995

B.Kim, \& T. Reeves. Reframing research on learning with technology: in the search of the meaning of cognitive tools. Instructional Science Journal, Springer, 35 (3), 207-256, 2007. Available at https://edit802fall10.pbworks.com/f/Kim\%20etal_Cognitive\%20Tools_2007.pdf (retrieved in 15/2/2015)

Yin, R.K. Case study research: design and methods. Newbury Park: Sage Publications, 2003.

Russek, B. E. \& S.L.Weinberg. Mixed methods in a study of implementation of technology -based materials in the elementary classroom. Evaluation and Program Planning, 16 (2), 131-142, 1993

R. Paul and L. Elder. The Thinker's Guide to How to Study and Learn. Dillon Beach, CA, USA: Foundation for Critical Thinking, 2001.

R. T. Johnson, \& D.W. Johnson. Action research: Cooperative learning in the science classroom. Science and Children, 24,31-32, 1986

B. J. Zimmerman. Theories of self-regulated learning and academic achievement: An overview and analysis. In B. J. Zimmerman \& D. H. Schunk (Eds.), Self-regulated learning and academic achievement: Theoretical Perspectives (pp. 1-37). NJ: Lawrence Erlbaum Associates, 2001.

Biggs, Tang Y (2007) Teaching for Quality Learning at University, 3rd edition, McGraw-Hill, England, 2007.

Gruwell, E. (Eds.) (2009). The Freedom Writers Diary: how a teacher and 150 teens used writing to change themselves and the world around them. New York: Broadway Books.

Zohar, A., \& Dori, Y. (2003). Higher Order Thinking Skills and Low-Achieving Students: Are They Mutually Exclusive? Journal of the Learning Sciences, 12 (2), 145-181

Abrami, P. C. , Bernard, R. M., Borokhovski, E.,Wade, A., Surkes, M.A., Tamim, R., and Zhang, D. Instructional Interventions Affecting Critical Thinking and Dispositions: A Stage 1 Meta-Analysis. Review of Educational Research, 78(4), 1102-1134, 2008.

Case, R. Moving critical thinking to the main stage. Education Canada, 45 (2), 45-49, 2005

D. Jonassen, Learning to Solve Problems: An Instructional Design Guide, San Francisco, CA, USA, 2004.

De Bono, E. Six Thinking Hats, Little, Brown and Company, Boston, USA, 1985.

Sharples, M. How we write: writing as creative design. London: Routledge, 1999.

Sampson, G. Writing Systems: A Linguistic introduction, Stanford University Press, California, USA, 1985.

Bastos, A. \& Ramos, A. O Youtube e o Pensamento de Ordem Superior em Inglês: Língua Estrangeira, pp. 915-925. Atas da VII Conferência Internacional de Tecnologias de Informação e Comunicação na Educação -Challenges 2011. (ISBN: 978-972-98456-9-7). Universidade do Minho. Braga, 2011.

Kennedy, M., Fisher, M.B., \& Ennis, R. H. Critical Thinking: Literature review and needed research. In L. Idol \& B.F. Jones (Eds.), Educational values and cognitive instruction: implications for reform (11-40). Hillsdale, New Jersey: Lawrence Erlbaum \& Associates, 1991.

Anderson, J.R., Reder, L.M., \& Simon, H.A. Situated learning and education. Educational Researcher, 25 (4), 5-11, 1996.

McPeck, J.E. Critical thinking and subject specificity: A reply to Ennis. Educational Researcher, 19(4), 10-12, 1990.

Paul, R. and Elder, L. Critical Thinking: Learn the Tools the Best thinkers Use. USA. Prentice Hall, 2005. 